\title{
The present situation of mechanical parameters in the ground test
}

\author{
Jiafeng Zhao ${ }^{1,}$, , Wei Wang ${ }^{2, b}$ \\ ${ }^{1,2}$ Ordnance Engineering College, Shijiazhuang 050003, China \\ a15398296968@163.com, bwangweiwill@126.com
}

Keywords: Terramechanics, mechanical parameters, ground test.

\begin{abstract}
Ground mechanics is the study of off-road driving machine interaction with the ground in a mechanical discipline, vehicle dynamics and soil mechanics is a goalkeeper of combining the interdisciplinary, involving vehicles, ground and its interaction research of dynamics, etc. Mechanical parameters test has important significance on the ground, this paper introduction the significance of mechanical parameters on the ground, the research methods, experimental instruments and equipment, the main achievements and conclusions, include the latest research progress in these areas. To carry out the ground of the institute of mechanics, with the aid of the ground of the mechanics theory and method are discussed. Finally the field of mechanical parameters of the ground test in the future research direction are discussed in this paper.
\end{abstract}

\section{Introduction}

This subject main driving cross-country vehicle ground mechanics of the interaction between the machine with the ground in the form of machine on the ground to walk by soil bearing, sinking depth of the traveling mechanism and mobile resistance related to its structural parameters and the characteristics of soil pressure; Walking mechanism through adhesion with the ground and destroy the shear resistance of the ground, producing machine along the required traction.

The ground mechanics is the study of the related problems in the off-road driving a discipline. Ground mechanics research area includes all kinds of soft ground, such as dirt, farmland, desert, snow, swamp, tidal flats and vegetation on the surface, and all kinds of the ground surface of the moon, Mars, machine includes a off-road vehicle, tractor, engineering machinery, armored vehicles, soil homework, planet detection machines, etc. As a branch of engineering mechanics, mechanical parameters of the ground test can for the people in the design process to predict the machine walks in particular in the soil properties, ensure the optimum running gear design, machine mobile performance evaluation and through sexual judgment to provide necessary theoretical and experimental basis ${ }^{[1]}$.

U.S. army engineers channel test station at the end of world war put forward the rapid determination of soil can be sexual cone index method, using a cone apex head, angle of $30^{\circ}$ pressure at a speed of about $3 \mathrm{~cm} / \mathrm{s}$ into the ground, the unit pressure cone bottom area known as the cone index.In particular soil test to the cone index and vehicle test had been done in comparison with the cone index of soil, can predict the vehicle in this particular soil through sex. Cone index method based on a vehicle, on the basis of extensive tests are carried out, not to delve into the vehicle and the mechanical effect relationship between soil, is a pure experience method in ground mechanics research.This method applicable convenient testing, is still widely used.

Determines the effect of interaction between soil and machine process of soil physical and mechanical parameters, baker, on the basis of referring to the methods of geotechnical soil mechanics, testing techniques and methods of the soil parameters, these parameters include the various physical parameters and mechanical parameters, such as baker used by cohesion, friction modulus of deformation, deformation modulus of soil deformation index $n$, using a formula expressing tablet on subsidence ${ }^{[2-3]}$.

$$
P=\left(\frac{K_{C}}{b}+K_{\varphi}\right) \cdot Z^{n}
$$


Considering the cohesion and internal friction Angle of c using the formula of two soil shear properties.

$$
\tau=(\mathrm{c}+\sigma \tan \varphi)
$$

The establishment of evaluation parameters and test method for simulation field in place provides the foundation soil in the laboratory and the theoretical calculation. Schematic diagram is shown below:

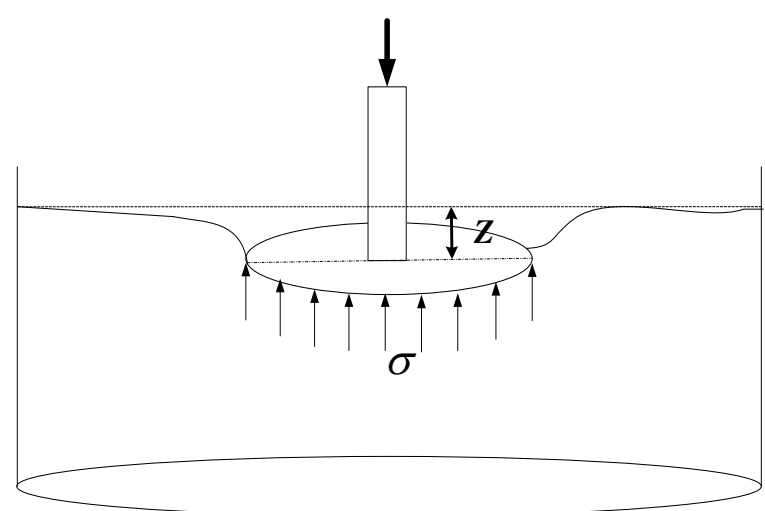

Fig.1 Sketch map about pressure-sinkage of plate

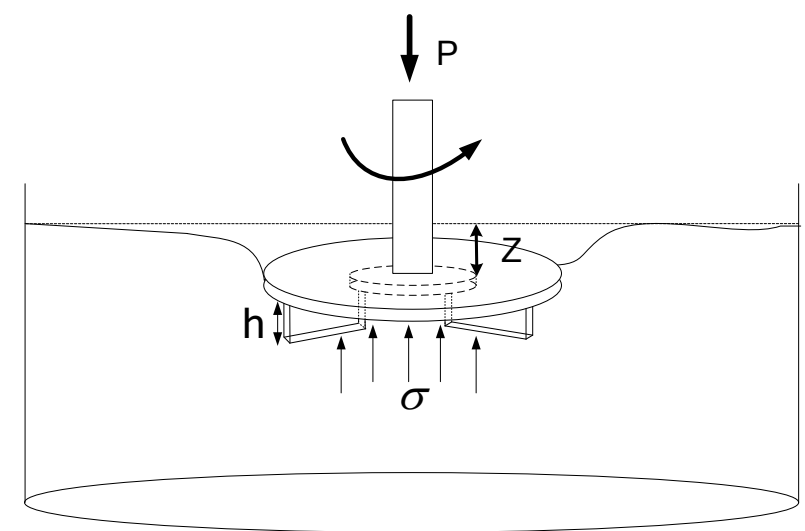

Fig.2 Sketch map about plate shear

\section{Theoretical Research Methods}

Theory research method refers to following the continuum mechanics method, studies the deformation and movement of soil, through research, the relationship between the stress and strain of soil, equilibrium conditions, boundary conditions to study soil damage and failure mechanism of this kind of method in vehicle in quantitative description of interaction between soil than the semi-empirical method is improved, but because of the complexity of the soil, the accuracy and applicability of the constitutive equation subject to certain conditions of the test. Mechanics in the ground soil as the elastic and plastic processing, mostly use to strengthen the elastoplastic constitutive relation. According to the constitutive relation is calculated under different loads and boundary conditions can be stress field, displacement field, to predict the machine on the ground walk through performance. Another method is to non-rigid soil as elastic-plastic material, using the limit equilibrium theory is analyzed, before don't consider to limit state, the process of using strength criterion to judge the soil's limiting equilibrium condition, the method based on the analysis of the shovel plate test pressure in the process of excavation and cone. Through the test can be used for the mechanical parameters of the soil, in the analysis of the wheels and soil interaction can calculate the ultimate bearing capacity of the soil ${ }^{[4]}$.

More researchers using general finite element software ABAQUS as analysis tool of machine interaction with soil, general software's advantage is can save development time, the finite element before and after processing is complete, the problem is that the soil constitutive model in software is less, can't completely adapt to the requirement of complex soil conditions, boundary conditions are 
set do not fully meet with the requirement of practical process. Other numerical method such as boundary element method and discrete element method has been applied in the study of discrete element method (particle flow software PFC2D / 3 D based on discrete dynamics, the analysis of the soil large has the advantage of discontinuous deformation ${ }^{[5]}$.

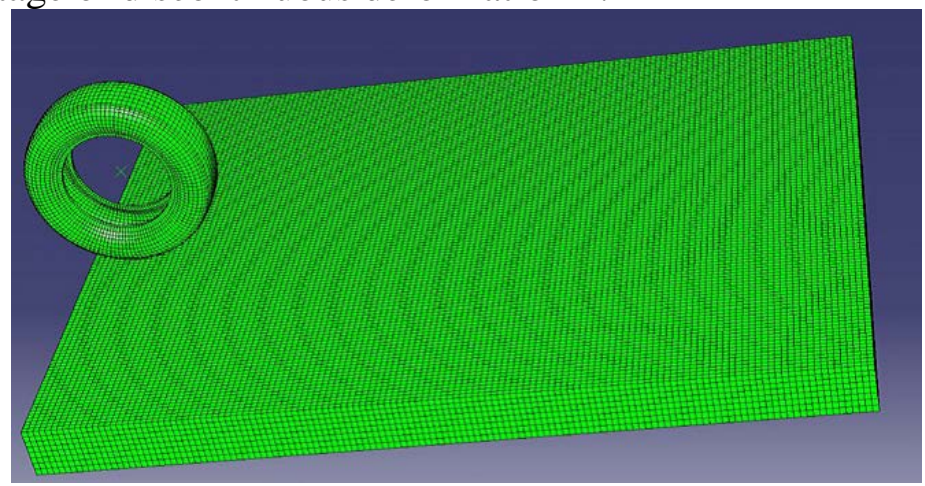

Fig.3 Finite element mesh for tire on soil.

\section{Test Methods}

Ground mechanics from the outset a paying equal attention to both theory and experiment of discipline, to simulate the ground machine interaction and observation record test data, to carry out the soil mechanical parameters test on the ground, using a variety of special test equipment, the U.S. army driving land of bayesian instrument laboratory use tablet and shear ring measured soil pressure and shear properties, and can automatically record the experimental data, large bayesian instrument by tractor traction, small, can carry on the field measurement by man. Cone penetrometer of cone index can be used as a judge a comprehensive parameters of soil strength, and determine intuitive, convenient and has been applied in field and laboratory test, field using the way of loading can be manually loaded or machine power load, the indoor load method can be used when using computer control $^{[6]}$.

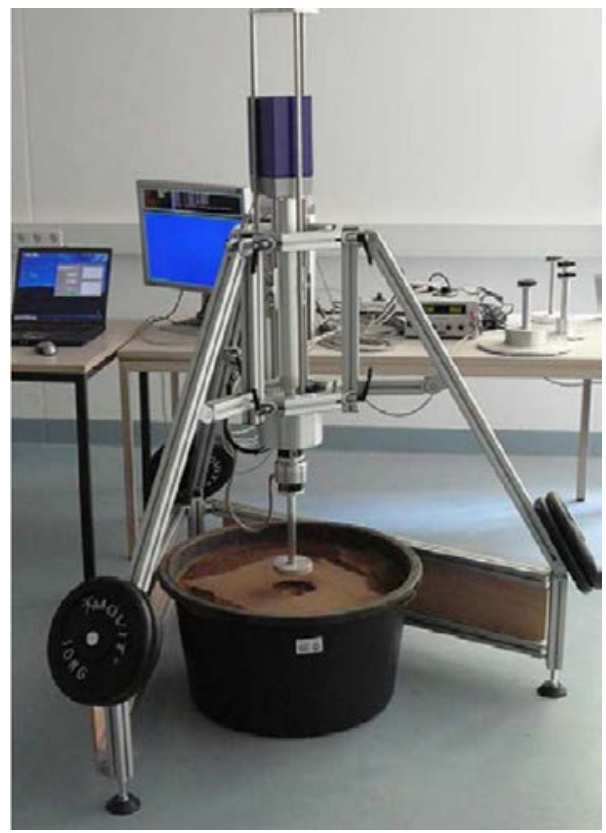

Fig.4 Bevameter for soil characterization.

Theoretical analysis of the soil mechanics parameters using geotechnical soil mechanics in the direct shear apparatus and triaxial confining pressure instrument measurement, direct shear experiments of soil failure load is directed along the predetermined plane, through the soil breakdown point Mohr stress circle envelope can determine the cohesion and internal friction Angle of soil, and the researchers such as baker USES the rectangular and circular shear plate, simulate the shoe or claw tire pattern vertical edge caused by shear, more press close to actual ground vehicle mechanics. 
Triaxial confining pressure test can measure soil sample at the same time the vertical deformation and horizontal deformation, axial compression ability of static load test, dynamic load test and stress path test, is used to verify the applicability of the various soil constitutive model.

\section{Conclusion and Prospect}

Ground mechanical parameters put forward after many years of development has been more mature, test methods and test instrument is relatively mature, but because of the complexity and uncertainty of the soil, there are still many deficiencies.

1) lack of targeted software development, the existing simulation software, such as finite element method, it is difficult to simulate the large deformation of the soil.

2) by the flat face space expansion, whether it is a widely used theory of baker, or experience method, mechanical model is basically a two-dimensional plane analysis on the ground, very few research of three dimensional space Angle. A two-dimensional model can only down to the stress and strain analysis of axisymmetric load situation. In cases where only the space Angle to analyze the axisymmetric load case can reflect the real situation of interaction with the ground.

3) exploration of the theory of innovation, most of existing research vehicle ground mechanics theory have been used for decades, and development is slow, for the study of ground mechanics has a very large space can not fully express the ground interaction method of theoretical analysis and simulation model of mechanics is based on the ground, the development of vehicle dynamics and soil mechanics research related scholars can use relevant theories in soil mechanics to introduce the development of soil mechanics, and promote the development of mechanics on the ground.

\section{References}

[1]. Sun Gang, Gao Feng, Li Wen . Terramechanics and its application in planetary exploration[J]. Advances in Mechanics, 2007, 37(3): 453-464.

[2]. Bekker M G. Introduction to Terrain-Vehicle Systems [M]. Beijing:China Machine Press, 1978. 2338-2346.

[3]. Zhuang Jide. Vehicle-Terramechanics [M]. Beijing:China Machine Press, 1980.

[4]. Zhang Kejian. Vehicel-Terramechanics[M]. Beijing: National Defence Industry Press, 2002.

[5]. Li Guangxin, Zhang Bingyin, Yu Yuzhen. Soil Mechanics[M]. Beijing: Tsinghua Press, 2013.

[6]. Wong J Y. Terramechanics and off-road vehicle engineering. [M]. Elsevier ,Oxford ,UK, 2010. 